\title{
O turismo como impulsionador do desenvolvimento regional: análise no Campo das Vertentes (MG), Brasil
}

Thiago de Sousa-Santos. Instituto Federal de Educação, Ciência e Tecnologia do Sul de Minas Gerais, Poços de Caldas, Brasil.

Raquel da Silva-Pereira. Universidade Municipal de São Caetano do Sul, São Paulo, Brasil.

RESUMo | Este artigo apresenta a pesquisa realizada com o objetivo de analisar os resultados gerados pelas açóes de fortalecimento do turismo para o desenvolvimento regional, a partir da dimensão organizacional proposta pelo modelo de Tomazzoni (2007). Foram investigados os municípios de Prados, São Joáo Del Rei e Tiradentes, localizados na regiáo denominada Campo das Vertentes no Estado de Minas Gerais. Houve pesquisa documental e foram realizadas 12 entrevistas, sendo os dados analisados por meio de análise de conteúdo utilizando software Atlas TI. Os resultados permitem afirmar que o Circuito Turístico Trilha dos Inconfidentes (СтTI), desempenha um papel de protagonista no que diz respeito ao desenvolvimento da atividade turística na região, exercendo maior poder e influência que outros atores sociais, enquanto instância de governança do turismo. Entretanto, observou-se um desequilíbrio referente ao desenvolvimento das açóes de turismo em nível municipal, diretamente relacionado à organização do Conselho Municipal de Turismo de cada município.

PALAVRAS-CHAVE | desenvolvimento regional e local, regionalização, planejamento do desenvolvimento.

ABSTRACT | The research presented in this article, has the purpose of analyzing the results generated by the actions to strengthen tourism for regional development, based on the organizational dimension proposed by the Tomazzoni (2007) model. We investigated the municipalities of Prados, São João Del Rei and Tiradentes, located in the region called Campo das Verentes in the State of Minas Gerais. The investigation was based on documentary research and twelve interviews, and the data were analyzed through content analysis using Atlas IT software. The results allow us to affirm that the Circuito Turistico Trilha dos Inconfidentes (CTTI) plays a leading role in the development of tourism activity in the region, exercising greater power and influence than other social actors, as an instance of tourism governance. However, there was an imbalance regarding the development of tourism actions at the municipal level, directly related to the organization of the Municipal Tourism Council of each municipality.

KEYWORDs | regional and local development, regionalization, development planning. 


\section{Introduçáo}

A crise dos modelos hegemônicos de desenvolvimento do pós Segunda Guerra Mundial, aliada ao processo de reestruturação ocorrido, têm afirmado as dimensôes regional e local como espaços privilegiados para promover o desenvolvimento (Storper \& Harrison, 1994; Rotta, Preuss \& Ames, 2006).

$\mathrm{O}$ questionamento das teorias que sustentavam as explicaçóes dominantes, a respeito do desenvolvimento após a Segunda Guerra Mundial, motivou um processo de reestruturaçáo produtiva que colaborou para a retomada dos estudos sobre o papel representado pelas regióes nas dinâmicas de desenvolvimento social (Rotta, 2007).

Esses novos estudos emergiram de contextos diferenciados e, a partir de múltiplas visões teóricas, puderam ser agrupados em dois grandes "sentidos": o regionalista e o globalista (Rotta, 2007). O sentido regionalista ressalta a perspectiva de territorialização do desenvolvimento, afirmando a especificidade dos espaços locais na definição das condiçóes do desenvolvimento e apontando para os problemas decorrentes das opçóes globalizadoras (Dallabrida, Siedenberg \& Fernández, 2004; Klink, 2001). Por sua vez, o sentido globalista sustenta-se na tese da homogeneização do espaço, em decorrência do processo de globalização e das transformaçóes produtivas e tecnológicas que ocorreram mundialmente, sobretudo no final do século xx (Rotta, 2007).

A valorizaçáo do regional em contraponto ao global vem contribuindo para que se discutam, com ênfase cada vez maior, questôes de natureza conceitual e teórica relativas à região, ao regionalismo e à regionalidade (Gil, Oliva \& Silva, 2009), sendo que esta última gera sinergia entre os diferentes stakeholders que se sentem pertencentes e uma mesma regiáo, da qual normalmente se orgulham.

Associado ao exposto, como fator de desenvolvimento econômico, o turismo pode gerar aumento e redistribuição de renda, por meio da comercialização de bens e serviços, no qual o turista gasta boa parte de sua renda em diferentes setores da economia. Como fator de desenvolvimento, a atividade turística pode contribuir com o aumento de empregos diretos e indiretos (Silveira, 2008).

No turismo, a imaginação coletiva criada, compartilha determinados valores públicos comuns que oferecem melhores oportunidades para o desenvolvimento humano. Tais valores estão relacionados à capacidade de gerar alegria, prazer ou bem-estar, decorrentes do encaixe entre necessidades e desejos, a partir e oportunidades abertas por meio dos serviços oferecidos (Medina, 2017).

Em virtude de sua importância econômica, a atividade turística torna-se um recurso para a população, uma vez que o emprego e a ocupação produzida pela atividade cria um mecanismo que inscreve sua capacidade de reestruturaçáo econômica, espacial e simbólica no espaço (Ramírez, Cortés, Osorio \& Nieto, 2017).

Além disso, por tratar-se de uma atividade que pressupóe determinado nível de estrutura organizacional, fundamentada nas necessidades e nas motivaçóes manifestadas pelos atores envolvidos, requer uma série de açôes voltadas ao atendimento dos requisitos da oferta e das exigências da demanda. Tais açóes, por sua vez, necessitam ser ordenadas em decisões pautadas em políticas públicas para o setor, as 
quais carecem de uma governança da atividade turística de forma institucionalizada, capaz de defini-las e implementá-las com legitimidade (Dreher \& Salini, 2010).

Nesse sentido, dentre os municípios de Minas Gerais que compóem o roteiro turístico denominado Estrada Real (ER), alguns localizados na mesorregiáo do Campo das Vertentes como São João Del Rei, Tiradentes e Prados se destacam, pois têm na atividade turística uma importante fonte de renda e ocupação para os munícipes. Além disso, dos municípios analisados Tiradentes é considerado um indutor nacional do turismo, seguido por São João Del Rei, considerado um indutor estadual e Prados que têm na atividade turística uma importante fonte de renda e ocupação, sendo os três municípios limítrofes que compóe a Região do Campo das Vertentes (Barbosa, 2008; Neves \& Carneiro, 2012; Oliveira \& Januário, 2007; Rodrigues, Silva \& Diniz, 2012).

Nos municípios supracitados, o turismo representa uma transformação nas bases econômicas e na organização social em âmbito regional. Essa transformação resulta de mobilização social que explora as potencialidades e capacidades específicas existentes na região. Identifica-se, ainda, na região, que outros municípios iniciaram um processo para desenvolver atrativos turísticos ou empreendimentos relacionados, tomando como exemplo positivo os municípios citados, que possuem maior desenvolvimento da atividade turística, sobretudo Tiradentes. Vale ressaltar que, para ser um processo consistente e sustentável, o turismo deve elevar as oportunidades sociais e a viabilidade da economia local, aumentando a renda e as formas de riqueza, desde que não impacte demasiadamente a natureza (Cirino \& Lima, 2008; Santos, 2011).

A pergunta que deu origem a esta pesquisa foi: quais os resultados gerados pelas açóes de fortalecimento do turismo para o Desenvolvimento Regional, a partir da dimensão organizacional proposta pelo modelo de Tomazzoni (2007)? Esse questionamento mostra-se relevante por permitir verificar o resultado das açóes já desenvolvidas e, ainda, possibilitar um entendimento das peculiaridades para um planejamento futuro. Os municípios selecionados compóem uma região na qual as atividades culturais, artesanais e turísticas são características marcantes, o que resultou, inclusive, na criação do Circuito Turístico Trilha dos Inconfidentes (CTTI), nome esse motivado pela representação histórica da região no período da Inconfidência Mineira.

\section{Referencial teórico}

\section{Dimensão organizacional do Turismo e Desenvolvimento Regional}

Considerando a necessidade de regionalização e gestão da atividade turística, Tomazzoni (2007) propóe a dimensão econômica do desenvolvimento regional a partir do turismo. Os elementos por ele identificados no desenvolvimento regional são: delimitação espacial; disparidades intrarregionais; externalidades; sustentabilidade ambiental e inclusão social. Quanto aos elementos do desenvolvimento do turismo, de acordo com o mesmo autor, destacam-se: oferta e demanda; desempenho; priorização; exportação; circuito produtivo; interatividade extrarregional; equalização intrarregional; e acessibilidade. 
A realização do objetivo principal do desenvolvimento regional ocorrido por meio do turismo, depende da gestão eficaz das três dimensôes e da gestão da articulação entre elas: a dimensão econômica, a dimensão organizacional e a dimensão cultural. Desse modo, cada elemento da dimensáo econômica e da dimensáo cultural se consolidará se houver açóes deliberadas, de acordo com aplicação dos elementos da dimensão organizacional. Assim, para identificar e diagnosticar a configuração da oferta turística é preciso planejamento e conhecimento, bem como a configuração da oferta é fundamental para conhecimento e mapeamento da realidade regional, visando a gestão sistêmica (Tomazzoni, 2007).

Para Tomazzoni (2007), os elementos da dimensão cultural do turismo, possuem a virtude de fortalecer valores de caráter cultural, antropológico e econômico. O autor defende que a cultura popular, a qual o turismo sintetiza, representa e projeta as relaçóes sócio-humanísticas que a atividade promove e, considerando a comunidade, consiste em todo o acervo de tradiçôes, modos de vida, costumes, sistemas de produção e expressóes de talentos.

Cada um dos elementos do desenvolvimento regional pode ser aplicado à dimensão cultural. No entanto, é preciso considerar a delimitação espacial com base nas identidades da cultura local, o que permite a identificação das externalidades geradas pela cultura, a sustentabilidade das identidades culturais e de como a cultura proporciona inclusão social. Da mesma forma, os elementos específicos do desenvolvimento do turismo regional aplicam-se à dimensão cultural, pois "a cultura regional constitui-se em uma oferta diversificada de atrativos, gerando um circuito produtivo e proporcionando o suprimento de demandas diversas de mercado" (Tomazzoni, 2007, p. 180).

Para viabilizar a integração dos elementos da dimensão econômica e cultural do turismo, Tomazzoni (2007) define como estruturantes da dimensão organizacional, os seguintes elementos: "poder e capital social", "gestão sistêmica", "divulgação e imagem", "mercadologia e comercialização", "planejamento, empreendedorismo e inovação e conhecimento" representados na figura 1.

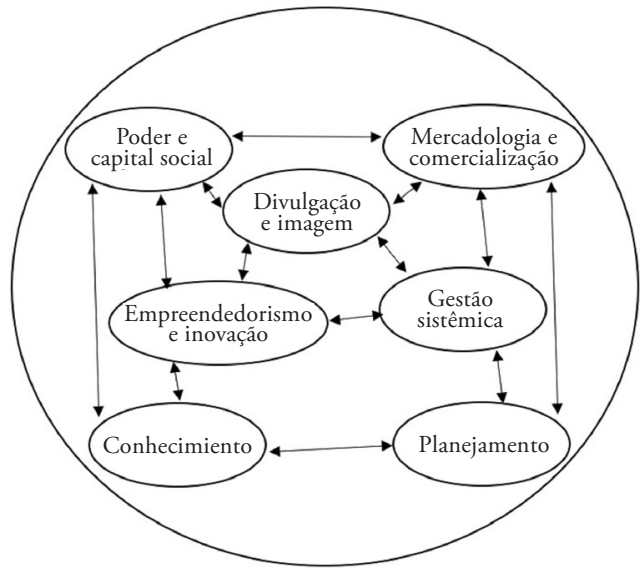

FIGURA I | Elementos da dimensão organizacional

FONTE: ADAPTADO DE TOMAZZONI (2007, P. I78) 
Por meio da gestão eficaz das três dimensões de Tomazzoni (2007), bem como da gestão da articulação entre elas, configura-se o desenvolvimento regional (Paixão, 2013). Assim, a oferta turística de qualidade depende de planejamento e conhecimento, que, por sua vez, possibilitará o conhecimento e mapeamento da realidade regional (Paixão, 2013; Tomazzoni, 2007). A articulação entre Estado e região é a chave do desenvolvimento, tanto no nível regional, como no nacional. Uma posição integradora do turismo, no processo de construção da região de destinos, facilitada pelo modo de mercantilização e institucionalização dos recursos territoriais no destino, é central para alcançar objetivos de desenvolvimento regional, induzido pelo turismo (Boisier, 1998; Stoffelen \& Vanneste, 2016).

Tomazzoni (2007) apresenta em seu modelo as dimensóes do Arranjo Produtivo Local (APL) turístico, destacando serem aglomeraçóes territoriais com foco em um conjunto específico de atividades econômicas, com vínculos e interdependências.

Nesse contexto, compreender o papel da governança na atividade turística e no desenvolvimento regional torna-se essencial para criar um ambiente de planejamento, tomada de decisóes, criação de regras e promoção da participação coletiva que possibilite o fortalecimento do turismo e seus efeitos na regiáo.

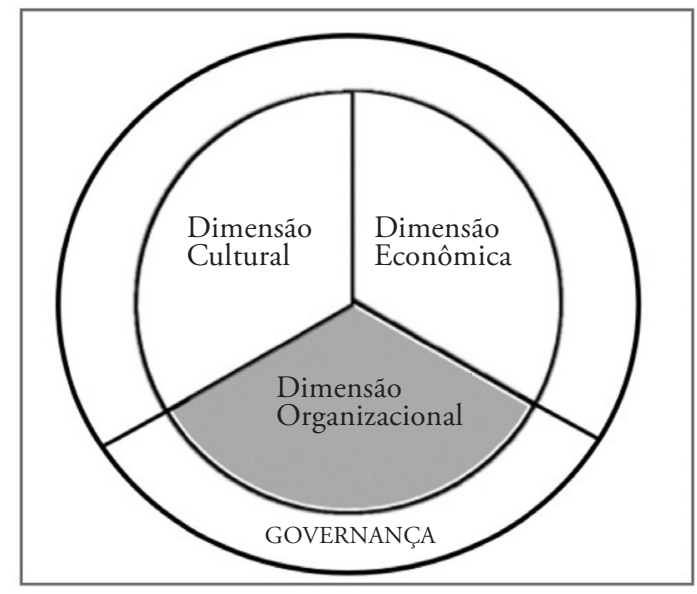

FIGURA 2 Dimensóes do APL turístico

FONTE: ADAPTADO DE TOMAZZONI (2007)

Com base no modelo de análise das três dimensôes de Tomazzoni (2007), foram analisados os resultados gerados pelas açóes de fortalecimento do turismo para o Desenvolvimento Regional, considerando os elementos da dimensão organizacional e suas características, levantados neste referencial teórico.

\section{Governança do turismo e desenvolvimento regional}

A governança pressupóe questôes diretamente relacionadas, tais como a descentralização das decisôes políticas e o ganho de poder pela sociedade para participar nos processos de tomada de decisão, podendo levar ao desenvolvimento regional (Paixão, 2013). 
A planificação do desenvolvimento regional é, antes de mais nada, uma atividade societária, no sentido de ser uma responsabilidade compartilhada por vários atores sociais: o estado, evidentemente, por razões várias e conhecidas, e a própria região, enquanto comunidade regional, polifacetária. (Boisier, 1998, p.47)

As relaçóes de poder que permitem estabelecer a governança não se tratam de relaçóes amistosas ou harmônicas, mas de relaçóes que ocorrem em processos conflituosos, o que pode gerar disputas (Dallabrida, 2011), por essa razão se deve buscar a construção de estratégias multiescalares e de governança multinível que contemplem diversas escalas espaciais, articuladas no território alvo do processo de desenvolvimento. Ainda que haja uma transferência de poder, deve-se relativizar esse poder conquistado pela sociedade, cercado de limitaçóes no que tange à sua efetividade.

No Brasil e em todo o mundo, liderança individual e institucional está ganhando cada vez mais importância no setor do turismo regional. Desde os anos 1990, o Brasil introduziu um leque de políticas sociais, reformas políticas e institucionais para modernizar a sua economia e facilitar o progresso social e econômico (Lohmann \& Dredge, 2012). Novas formas de governança do turismo regional incorporando parcerias público-privadas estáo sendo introduzidas. A responsabilidade institucional movimenta-se do centro para os níveis regionais, e o bastão da liderança tem sido passado do governo nacional para Regional Tourism Organisations (RTOs) (Araujo \& Dredge, 2012).

Estudos de gestão de destinos turísticos sugerem que a capacidade de uma organização de turismo, para implementar estratégias sustentáveis de forma eficaz, envolve partilha de poder, colaboração e acordos conjuntos entre a obtenção de recursos dos setores público e privado (Bramwell \& Lane, 2011; Jamal \& Getz, 1999).

Neste sentido, a estrutura de coordenação e gestão descentralizada do turismo visa cumprir a função de articulação, em todos os elos da cadeia de relacionamento, destacando, sobretudo, as instâncias de representação regional do turismo, em que a atividade se realiza. A partir dessa estrutura, a criação dos Conselhos Municipais de Turismo (COMTur) foi essencial para a organização de instâncias de representação regional, formando assim o sistema nacional de gestão do turismo (Brasil, 2007).

O comtur é um órgão vinculado à administração municipal, constituído por representantes do poder público, empresariado e sociedade civil. No entanto, cada município tem autonomia para determinar quem e quantos seráo estes representantes através de lei municipal. Nos municípios analisados, a composição do comTuR se dá por membros do Poder Público Municipal representados por pessoas vinculadas ao Departamento Municipal de Meio Ambiente e Poder Legislativo Municipal.

Compondo tal sistema, as Associaçóes de Circuitos Turísticos, respeitando a composição diversificada nas dimensôes cultural e natural do Estado de Minas Gerais, com 447 municípios, passou a ser a instância de governança regional. Os circuitos turísticos constituem-se em agrupamentos de municípios com características turísticas semelhantes, localizados dentro de uma região geográfica limitada, que se unem para organizar e desenvolver a atividade de forma sustentável, ampliando adequadamente o potencial do turismo, buscando limitar seus danos e 
estimulando o desenvolvimento regional (Souza, Warley, Shiki \& Pereira, 2015). Podem associar-se ao circuito o poder público e membros da sociedade civil (Santos \& Gomes, 2007).

Por meio de representação no COMTUR, estruturando uma rede de governança do turismo de forma regionalizada, uma gestão unificada e participativa, a associação de circuito turístico tem a autonomia de representar seus municípios integrantes na política de turismo do Estado, encaminhando projetos, solicitando recursos, entre outras atividades. Além disso, apenas se integrado a circuitos turísticos, um município pode ser contemplado pela política de recursos turísticos estaduais (Ramos, 2007).

\section{Metodologia}

Para este estudo adotou-se uma abordagem qualitativa de investigação. O tipo de pesquisa é exploratória, pois auxilia a compreender melhor uma situação, conhecer as características de um fenômeno e ainda procurar explicaçóes causais e também as consequências do fenômeno (Mattar, 1996). Foi utilizado como método o estudo de caso, uma investigaçáo empírica em profundidade realizada no contexto da vida real de fenômenos contemporâneos (Yin, 2015).

Foram utilizadas diversas fontes de dados secundários, a partir da revisão de literatura nacional e internacional, tais como livros, periódicos, anais de eventos, journals e outros documentos consultados via internet, além de dissertaçóes e teses, com a intenção de aprofundar o conhecimento referente ao assunto pesquisado. Foi utilizada a pesquisa documental, incluindo projetos de execução, relatórios de gestão e estatutos, consultados nas prefeituras e instituiçóes que fazem parte deste estudo.

Para a coleta de primários, com base em Reich e Benbasat (1996), realizou-se um roteiro semiestruturado que permitiu que fossem realizadas 12 entrevistas. Os sujeitos entrevistados são diversos atores envolvidos na atividade turística: o poder público, pelos secretários(as) de Turismo, representantes dos Conselhos Municipais de Turismo; Instituiçôes de apoio como o Serviço Brasileiro de Apoio às Micro e Pequenas Empresas (sebrae); Presidentes de Associaçóes Comerciais; Empresários de setores ligados diretamente à atividade turística; Instâncias de Governança, como Instituto Estrada Real e Circuito Turístico Trilha dos Inconfidentes.

Como ferramenta de análise dos dados, utilizou-se o software Atlas TI, versão 7, um aplicativo de informática concebido para a análise qualitativa de dados, sob a forma de texto, imagens e ou registro sonoro, utilizando técnicas de codificação e categorização (Mello, 2006), para auxílio na análise de conteúdo categorizado.

\section{Resultados e discussáo}

Conforme a análise dimensional do turismo e desenvolvimento regional proposta por Tomazzoni (2007), observam-se pontos comuns nos três municípios analisados, quanto aos sete elementos da dimensão organizacional, referentes ao poder e capital social, gestão sistêmica, divulgação e imagem, mercadologia e comercialização, planejamento, empreendedorismo e inovação e conhecimento. 
De acordo com Tomazzoni (2007), o elemento poder e capital social consiste nas organizaçóes, entidades e empresas públicas e privadas que exercem poder econômico, poder político e poder simbólico sobre as decisóes do Turismo em cada município.

Na tabela 1 é possível observar que o CTTI está presente entre as instituiçóes e instâncias de decisão nos três municípios analisados, sendo a instância com maior influência no turismo regional. Tal constatação foi feita, a partir dos relatos das entrevistas, documentos consultados, como estatutos dos Conselhos Municipais de Turismo em que o CTTI possui representatividade e relevante participação, Lei Estadual no 13.341 de 2000, artigos científicos sobre o tema, dentre outras fontes (СтTI, 2010; Oliveira \& Fuchs, 2013; Oliveira \& Januário, 2007; Secretaria de Estado do Turismo [SETUR], 2007):

\begin{tabular}{|l|l|l|}
\hline \multicolumn{1}{|c|}{ ELEMENTO } & \multicolumn{1}{|c|}{ MUNICíPIO } & \multicolumn{1}{c|}{ INSTITUIÇÓES } \\
\hline \multirow{4}{*}{$\begin{array}{l}\text { Poder e } \\
\text { Capital Social }\end{array}$} & Prados & Secretaria de Turismo e Cultura / COMTUR / CTTI \\
\cline { 2 - 3 } & Tiradentes & Secretaria de Turismo e Cultura / COMTUR / CTTI / Asset \\
\cline { 2 - 3 } & São João Del Rei & $\begin{array}{l}\text { Secretaria Municipal de Cultura, Turismo, Esporte e Lazer / } \\
\text { COMTUR / CTTI / ACI }\end{array}$ \\
\cline { 2 - 3 } & Região & CTTI / Secretaria Estadual de Turismo / IER \\
\hline
\end{tabular}

TABELA I | Instituiçóes que exercem poder e capital social

FONTE: ELABORADO PELOS AUTORES

Quanto ao poder político e simbólico nos municípios, o comTur possui um papel central nas decisóes relacionadas ao turismo, considerando uma variação no grau de influência de cada conselho, nos respectivos municípios, com destaque para o comtur de Tiradentes, que apresenta maior influência sobre as decisóes do município.

Em perguntas relacionadas ao planejamento da atividade turística no município de Tiradentes, a prestação de contas e as articulaçôes das açóes, foram demonstrados nos relatos a relevância do COMTur do município nas decisóes que são tomadas no que se refere ao turismo:

Através do COMTUR. Tudo através do COMTUR. Qualquer questão que direcionado que tem envolvimento direto ou indireto com o turismo é discutido no COMTur. (Entrevistado 1)

As associaçóes que exercem maior poder no turismo é a Asset e o COMTUR. Muito do comtur, porque ele é deliberativo, então tem um poder maior, mas eu acho que a associação tem a maioria das coisas que passam e temos um poder grande.

(Entrevistado 2)

É tudo decidido dentro do Conselho. (Entrevistado 11)

Apesar dos três municípios em análise possuírem Conselho Municipal de Turismo, o de Tiradentes é referência no quesito atuação, inclusive para os representantes dos Conselhos de Prados e de São João Del Rei. A Associação Empresarial de Tiradentes (ASSET), também possui papel relevante nas açôes de turismo no município e tem sua representatividade no COMTUR. 
O Instituto do Patrimônio Histórico e Artístico Nacional (IPHAN) que consiste em uma autarquia federal, filiada ao Ministério da Cultura, responsável pela preservação do Patrimônio Cultural Brasileiro é outra instituição representada no COMTUR com grande influência nas açôes desenvolvidas no município. A instituição foi apontada em relatos dos entrevistados como muito restritiva, em virtude de todo o patrimônio arquitetônico tombado em Tiradentes.

Outras instituições/instâncias, tais como Associação de Moradores, Instituto Histórico e Geográfico, Agência de Receptivo Turístico, sesi/fiemg, Poder Legislativo e Departamento de Meio Ambiente, são as demais representaçóes que compóem o comtur de Tiradentes.

Já no município de Prados, a representação do Conselho Municipal de Turismo possui representação dos seguintes órgãos: Executivo Municipal; Poder Legislativo Municipal; setor de Hospedagem; setor de Alimentação; setor Rural e Meio Ambiente; segmento Artístico; Associaçóes de Bairro; cтті. Quando perguntado sobre a instituição com maior poder, о СтTі е о COMTUR foram apontados pelos entrevistados como instituiçóes/instâncias de maior influência, seguido da Associação das Cidades Históricas. A Secretaria Municipal de Turismo e Cultura é considerada a maior fomentadora da atividade e não foi constatada uma atuação ativa da Associação Empresarial perante as açôes de turismo no município, fato que pode ser observado na própria representação no COMTUR, em que há representantes de setores específicos, mas náo da Associaçáo Empresarial.

Em São João Del Rei, a composição do comtur é formada por: indicado pelo Executivo Municipal; representante do segmento Empresarial (ACI); Secretaria Municipal de Turismo; Conselho Municipal de Patrimônio; Associação Regional Produtores Agrícolas (ARPA); CTTi; Associação de Hotéis e Pousadas de São João Del Rei, e Secretaria Municipal de Obras e Serviços Urbanos.

O poder e influência do comtur de São João Del Rei não foram mencionados nas entrevistas. Ao contrário, foi mencionado que o Conselho é pouco atuante, se comparado ao CTTI e ao IER. Por sua vez, a representatividade empresarial ocorre pela ACI, que consegue levar as demandas para a Secretaria de Turismo, CTTI, SEBRAE, IPHAN e demais instituiçóes atuantes no município.

Com base nos relatos coletados sobre poder e capital social das instituiçóes em São João Del Rei, observa-se que a Secretaria Municipal de Cultura, Turismo, Esporte e Lazer, por meio da superintendência de turismo foi apontada como o órgão de maior influência e poder sobre as decisôes de turismo no município. Vale ressaltar que no próprio Plano Municipal de Turismo, uma das diretrizes é desenvolver o COMTUR.

O comtur de São João Del Rei, comparado aos Conselhos dos demais municípios analisados, talvez não desenvolva um papel de expressiva relevância nas decisóes sobre turismo, especialmente se comparado ao comTur de Tiradentes. Outro ponto a ser observado é que, na própria composição do Conselho, não existe uma representatividade direta da população, como, por exemplo, membro de associaçáo de bairros, diferentemente dos Conselhos de Prados e de Tiradentes, que possuem representantes. 
Constatou-se que o CTTI é a instituição que mais influencia o turismo regional no Campo das Vertentes. Programas, projetos e açóes de turismo em nível estadual, direcionados pela Secretaria Estadual de Turismo, são planejados e executados pelo CTTI. No passado, considerando o período de consolidação do roteiro da Estrada Real, até por volta de 2007, o IER possuía um papel de grande relevância no desenvolvimento do turismo náo só na região, como em todo o Estado de Minas Gerais. Entretanto, com o fortalecimento dos Circuitos turísticos, as limitaçóes de atuaçáo do IER e alguns conflitos e dificuldades enfrentadas pela instituição, hoje não se percebe, nos municípios analisados e na região do Campo das Vertentes, um papel de liderança da atividade turística exercida pelo órgão que, inclusive, possui representatividade legal apenas no Comtur de Tiradentes, não participando de decisóes nos demais Conselhos.

De acordo com Tomazzoni (2007), ainda se tratando de poder e capital social, é importante destacar o orçamento dos municípios referente à atividade turística. Deste modo, conforme dados disponíveis nos portais dos municípios, link "transparência”, com base na fundamentação legal: art. $2^{\circ}$, inciso x - Instrução Normativa $\mathrm{n}^{\circ}$ 28/1999 - TCU, os orçamentos anuais de despesas nos anos de 2014, 2015 e 2016 apresentaram os seguintes números (tabela 2):

\begin{tabular}{|c|c|c|c|}
\hline & $\begin{array}{c}\text { SECRETARIA TURISMO } \\
\text { E CULTURA } \\
\text { (*ESPORTE E LAZER })\end{array}$ & $\%$ & $\begin{array}{c}\text { TOTAL DESPESAS } \\
\text { DO MUNICÍPIO }\end{array}$ \\
\hline \multicolumn{4}{|l|}{2014} \\
\hline Prados & $448.100,00$ & 2,83 & $15.816 .186,00$ \\
\hline Tiradentes & $697.480,00$ & 2,71 & $25.710 .607,48$ \\
\hline SJDR * & $4.005 .800,00$ & 2,16 & $185.314 .000,00$ \\
\hline \multicolumn{4}{|l|}{2015} \\
\hline Prados & $718.500,00$ & 4,41 & $16.307 .477,00$ \\
\hline Tiradentes & $952.905,00$ & 4,27 & $22.303 .879,00$ \\
\hline SJDR * & $2.418 .500,00$ & 0,96 & $250.926 .440,00$ \\
\hline \multicolumn{4}{|l|}{2016} \\
\hline Prados & $734.900,00$ & 4,24 & $17.331 .073,00$ \\
\hline Tiradentes & $950.130,00$ & 3,97 & $23.939 .580,00$ \\
\hline SJDR * & $2.247 .000,00$ & 0,94 & $238.945 .158,00$ \\
\hline
\end{tabular}

TABELA 2 | Orçamento anual de despesa 2014, 2015 e 2016

FONTE: PORTAL TRANSPARÊNCIA MUNICIPAL (2OI7)

Somente os municípios de Prados e Tiradentes possuem Secretaria Municipal exclusiva de Turismo e Cultura. O Município de São João Del Rei detém uma secretaria integrada de cultura, turismo, esporte e lazer, dividida em superintendências. Deste modo, o orçamento divulgado no portal de transparência do município possui valores globais das secretarias e não subdivididos por superintendências, comprometendo, assim, uma análise precisa de investimentos realizados, especificamente, na área de cultura e turismo. 
Em uma análise geral, observa-se que o município com menor orçamento para a Secretaria de Cultura e Turismo é o de Prados, seguido por Tiradentes e, posteriormente, São João Del Rei. Neste último, o orçamento é integrado com as áreas de esporte e lazer. No entanto, considerando o valor total do orçamento dos municípios em termos percentuais, o município que tem o maior percentual do orçamento total investido em turismo e cultura, é Prados, considerando os últimos três anos. Sáo João Del Rei, apesar de ter o maior valor em termos absolutos, investido nas áreas de turismo, cultura, esporte e lazer, considerando o orçamento total, é o que possui o menor percentual investido nessas áreas.

\section{Gestão sistêmica}

A gestão sistêmica do turismo no Campo das Vertentes é comandada pelo CTTI. A coordenação das açôes, o desenvolvimento do ambiente cultural favorável à comunicação e cooperação são pontos relevantes apontados nos relatos dos entrevistados, que afirmam o grande movimento de prefeitos no СтTі, na atualidade.

Por sua vez, constatou-se a influência do CTTI, do IER, da Secretaria Estadual e do SEBRAE como fundamental para a articulação de açóes que beneficiam o turismo e o desenvolvimento.

A existência de coordenação regional centralizadora e articuladora, para implementação de planos, a articulação e organização das entidades responsáveis pela gestão do turismo são aspectos essenciais na gestão sistêmica do turismo (Tomazzoni, 2007), papel este que nos três municípios analisados e na região do Campo das Vertentes vem sendo exercido pelo CTTI.

Entretanto, vale destacar uma limitação estrutural do CтTı, que, em virtude da equipe bastante reduzida, encontra restriçóes de atuaçáo perante a extensáo em que o circuito atua.

\section{Divulgação e imagem}

O trabalho de divulgação da imagem regional ocorre de maneiras distintas. Existe a divulgação geral do destino Estrada Real, cujo apelo mercadológico gerou benefícios na imagem dos municípios que compóem esse destino turístico. O papel de divulgação e fortalecimento da imagem ER é realizado pelo IER, que possui como um dos principais objetivos realizar o marketing do destino. A estratégia de divulgação utiliza mídias digitais, rádio, televisão, revistas, jornais, participação em feiras e exposiçóes, produtos como passaporte da ER, parceria com montadoras para montagem de versão especial de veículos com o tema ER, instalação de marcos em todo destino turístico, dentre outros.

O passaporte ER, desenvolvido pelo IER, possibilita ao turista registrar os municípios visitados no roteiro. No percurso existem diversos pontos de carimbo, nos quais, após percorrer todas as cidades de um dos Caminhos da ER é possível solicitar um Certificado. Caso o turista percorra os quatro Caminhos da ER e obtenha todos os carimbos, ele poderá solicitar o Certificado Especial. Os marcos da ER são sinalizaçóes presentes em todo o roteiro, a fim de orientar o turista. Cada marco possui informaçóes históricas sobre o local no qual está instalado com coordenadas geográficas. 
Quanto à divulgação mais regional, restrito ao Campo das Vertentes, о CTTI desenvolve tal função, mas sem se desvincular da imagem da ER. Tanto é que, em vários eventos e feiras, são estabelecidas parcerias, para que tanto a marca ER, quanto a marca do СтTі, sejam divulgadas de forma conjunta.

O стті desenvolve um importante papel de articulação entre os municípios, tanto no planejamento das açóes, definição de calendário de eventos, viabilizaçáo financeira, suporte na elaboração de políticas e planos de turismo, quanto na divulgação das localidades turísticas regionais.

Nos três municípios analisados, o conjunto arquitetônico, a religiosidade, a musicalidade, o artesanato são aspectos marcantes que despertam no turista a busca por atrativos culturais, históricos e gastronômicos na região. A imagem da regiáo é vinculada à história do país, à exploração do ouro, à tradição das festividades religiosas, às artes sacras, ao barroco mineiro e às festas tradicionais que preservam os costumes e ritos. Deste modo, o posicionamento da regiáo em cenário nacional quanto à referência no turismo histórico proporciona a visibilidade de uma imagem turística diferenciada.

\section{Mercadologia e comercialização}

A estrutura turística da região dispóe de variados tipos de hotéis, pousadas e restaurantes, principalmente, no município de Tiradentes. Nos municípios, dois restaurantes já foram listados no ranking dos 50 melhores do país, de acordo com o Guia Quatro Rodas (2012). No ranking, o restaurante é avaliado, de acordo com uma ficha técnica desenvolvida pelo Guia Quatro Rodas que avalia o couvert, a entrada, o prato principal e a sobremesa. Tiradentes possui ainda pousadas premiadas com certificado de excelência do TripAdvisor, que premia os estabelecimentos do setor de turismo e hotelaria que oferecem um serviço de alta qualidade.

O Comércio, em geral, é bastante intenso na regiāo, com destaque para o de São João Del Rei, que, por ser uma cidade polo regional, possui uma infraestrutura comercial diversificada que atende tanto o município, como outras cidades vizinhas.

De acordo com informaçóes divulgadas no portal das prefeituras dos municípios, foi possível levantar os números de eventos com ediçóes anuais realizadas nos municípios analisados (tabela 3):

\begin{tabular}{|l|c|c|c|}
\hline \multicolumn{1}{|c|}{ EVENTOS } & PRADOS & SÃO JOÃO DEL REI & TIRADENTES \\
\hline Festas / Feiras & 9 & 12 & 9 \\
\hline Festivais & 1 & 2 & 8 \\
\hline Exposições & 1 & 2 & 1 \\
\hline Encontros & 2 & 2 & 1 \\
\hline Congressos/Conferências & - & 1 & - \\
\hline Seminários & - & 1 & - \\
\hline Manifestaçóes desportivas & 2 & 1 & 3 \\
\hline Outras manifestaçóes & 1 & 3 & 1 \\
\hline
\end{tabular}

TABELA 3 | Número de eventos anuais nos municípios

FONTE: ELABORADO PELOS AUTORES A PARTIR DOS PORTAIS OFICIAIS DAS PREFEITURAS MUNICIPAIS (2OI7) 
São João Del Rei possui uma boa infraestrutura como centro de convenções, auditórios, teatros capazes de sediar eventos com um grande número de pessoas. Tiradentes possui tradição em sediar grandes festivais, como o Festival de Gastronomia, Tiradentes Vinho e Jazz Festival, Mostra de Cinema, entre outros. Prados, apesar de possuir infraestrutura limitada e pouca tradição em grandes eventos, atraindo turistas de várias regióes. Como exemplo, pode-se citar o Carnaval de Rua, Festival de Música, Exposição Agropecuária e Feira Artesanal.

$\mathrm{O}$ marketing desenvolvido na região inclui produtos e serviços que envolvem o resgate cultural, com museus, igrejas e casarôes centenários; o roteiro gastronômico com ênfase na culinária mineira; as artes com grupos teatrais, visitas guiadas, contação de histórias e lendas da região; o artesanato com destaque para peças produzidas em estanho, madeira, ferro, couro; a música com orquestras e grupos centenários; o turismo rural em fazendas do século XviII e XIX; a visitação a vilas e colônias italianas e o turismo de aventura, com roteiros de trilhas pelas Serras de São José e Serra do Lenheiro, cachoeiras e prática de esportes radicais.

Atualmente, são ofertados roteiros regionais para os turistas. O roteiro regional envolve a visita ao distrito de Bichinho, Prados, Resende Costa e Coronel Xavier Chaves, e visa apresentar o artesanato produzido nos municípios; visitar alambiques e apreciar as belezas naturais é uma opção a mais para conhecer municípios tradicionais na produção do artesanato. Outro roteiro refere-se ao passeio de Maria Fumaça, que vai de São João Del Rei à Tiradentes, considerado o mais tradicional dos passeios, para quem visita os municípios. Consiste na travessia de $12 \mathrm{~km} \mathrm{em}$ meio à diversidade ecológica presente no trajeto e paisagens, além da arquitetura peculiar do século XIX, ainda preservada. Existem, ainda, outros roteiros locais, por exemplo, em Tiradentes, o Tour Gastronômico e, em São João Del Rei, o Lendas Sanjoanenses.

\section{Planejamento}

A atividade turística no Campo das Vertentes passou a se desenvolver, a partir dos anos 1980, com maior reconhecimento do valor histórico, patrimonial e arquitetônico das antigas edificações dos municípios. Em meio a esse processo, algumas açóes de preservaçáo e o forte apelo da mídia, sobretudo, em Tiradentes, vieram fortalecendo a atividade na região.

Com o aumento de pessoas envolvidas na atividade artesanal, os eventos que foram sendo realizados nos municípios, a criação de novas empresas no setor de hotelaria e alimentação, melhoria da infraestrutura viária e um novo conceito social de valorização das tradiçóes e da cultura local, contribuíram para o desenvolvimento do turismo na região.

Com a criaçáo do Conselho Estadual de Turismo (anos 1990), foi criado o Plano Integrado para o Desenvolvimento do Turismo no Estado de Minas Gerais. A partir disso, vários polos turísticos foram sendo implantados. A Secretaria Estadual de Turismo foi criada e estabeleceu a Política Nacional com foco nos circuitos turísticos.

Em 1999, com a criação do produto turístico ER, a região do Campo das Vertentes passou a ter uma relevância maior na atividade turística, pois passou a fazer parte do planejamento estratégico da ER em nível estadual. 
Já nos anos 2000, com a fundação do CTTI, as açóes de desenvolvimento do turismo na região passaram a ser planejadas com uma perspectiva mais local e regional, levantando demandas, oportunidades, ameaças, pontos fortes e pontos fracos dos municípios. As prefeituras passaram a dispor de suporte e know how sobre a atividade, possibilitando substancial melhoria na criação de planos, políticas e açóes de turismo. Conforme apontado por Dallabrida, Siedenberg e Fernández (2004), observa-se neste caso a prevalência do sentido regionalista sobre o globalista na perspectiva de territorialização do desenvolvimento.

Dentre os municípios analisados que passaram a dedicar-se mais ao desenvolvimento da atividade turística, destaca-se Tiradentes, que se organizou mais rapidamente e possui atualmente instâncias de tomada de decisóes sobre atividades bem consolidadas, projetos de turismo em curto e médio prazos, Fundo Municipal de Turismo, legislação, regulamentação e controle de açóes que impactam diretamente o bom desempenho do turismo no município, que desenvolveu uma consciência social junto à população sobre a importância da preservação do patrimônio para que se tenha um turismo sustentável que possa se manter por muitas geraçóes.

Em São João Del Rei o turismo foi sendo planejado no decorrer do tempo pelo poder público municipal, mas com muitas variaçôes nas prioridades dos projetos e planos desenvolvidos. Vários governos que assumiram a prefeitura preocuparam-se em desenvolver políticas muito voltadas para o período do mandato, sem desenvolver um plano em longo prazo para o desenvolvimento da atividade turística no município. Deste modo, muita descontinuidade foi percebida ao longo do tempo, principalmente em períodos de mudança de governo. Fato agravante para tal cenário vivido no município é a baixa atuação do Conselho Municipal do Turismo, de modo que a maior responsabilidade pelas decisóes desta área fica a cargo da Secretaria Municipal de Turismo.

Já no município de Prados, a atividade turística possui um volume menor, se comparado aos demais municípios. Entretanto, existe uma estruturaçáo da cidade para buscar um melhor desenvolvimento dessa atividade, muito motivado pelo destaque do distrito de Bichinho, nos últimos anos, pela oferta de produtos e serviços turísticos que passaram a ser reconhecidos como diferenciados na regiáo. $\mathrm{O}$ Município possui um comTur atuante, mas ainda demanda um adequado planejamento a médio e longo prazo para fortalecimento da atividade.

Nesse contexto, о СтTі busca atuar de forma a equalizar e sintonizar as açóes de turismo desenvolvidas na região, a fim de que haja uma valorização do potencial turístico de cada cidade, apesar da competição existente entre os municípios, pela oferta de produtos e serviços turísticos, para que prevaleça o espírito de cooperação e uniáo entre eles para o desenvolvimento da atividade como um todo na região do Campo das Vertentes.

\section{Empreendedorismo e inovação}

Como visto, a região do Campo das Vertentes tem, em seu patrimônio histórico, arquitetônico e cultural, a motivação para o desenvolvimento do turismo. As cidades históricas de São João Del Rei, Prados e Tiradentes se destacam das demais da região 
por possuírem essa característica semelhante entre si, pelo período de exploração do ouro, pela Coroa Portuguesa e por sua proximidade geográfica.

O perfil dos empreendedores é bastante variado, pois tanto em Prados quanto em Tiradentes diversos empreendimentos têm origem familiar e se desenvolveram, expandiram e se diversificaram com o tempo. Já em Tiradentes, percebe-se um movimento diferente. Apesar de diversos empreendedores serem naturais do município, uma boa parte de empresários não nasceu em Tiradentes e alguns nem mesmo em cidades vizinhas. Com o crescimento do Turismo na cidade, logo nos anos de 1990, estendendo-se para os anos 2000, muitas pessoas de outras regióes do Brasil e grupos empresariais como a Rede Globo, vislumbraram uma oportunidade da cidade se consolidar como um forte destino turístico e, assim, passaram a investir nela. Percebe-se, atualmente, uma forte valorização imobiliária, principalmente, no centro histórico que se expandiu para outros bairros do município, com uma oferta diversificada de hospedagens, desde a clássica e simples ao luxuoso e refinado. $\mathrm{O}$ setor de alimentação também acompanhou esse movimento, sendo possível degustar tanto a tradicional culinária mineira, como a alta gastronomia mundial. Tiradentes é considerado assim, na atualidade, como um destino turístico com foco num público mais restrito, de alta renda e que exige produtos e serviços de excelência.

Por Tiradentes ter se tornado destaque na atividade turística da região, muitos empreendedores de cidades vizinhas perceberam uma oportunidade de utilizar a cidade como "vitrine" de seus produtos e serviços. São comuns, no município, muitas lojas que comercializam artesanato, entretanto os produtos que são vendidos nos estabelecimentos, normalmente, são produzidos em diversos outros municípios da região. Vale destacar, ainda que, entre os municípios que compóem o CTTI, muitos deles possuem uma especialização na produção artesanal, como, por exemplo, Resende Costa, na produção de peças utilizando o tear; São Tiago, na produção de biscoitos artesanais; Prados, na produção de itens em couro e madeira; Santa Cruz de Minas, na produção de móveis e artesanato em ferro; São João Del Rei, na produção artesanal de Estanho.

\section{Conhecimento}

A região dispóe de três instituiçóes de Ensino Superior: Universidade Federal de São João Del Rei (ufSJdr), Centro Universitário Presidente Tancredo de Almeida Neves (uniptan) e Instituto Federal de Educação, Ciência e Tecnologia do Sudeste de Minas Gerais, todos localizados no município de São João Del Rei. Os cursos oferecidos pelas instituiçóes são os mais diversificados, com destaque para UFS que oferece cursos não tấo convencionais como o curso de Música, curso de Teatro e curso de Artes Aplicadas todos em nível superior. Até o ano de 2010, o Uniptan oferecia o curso de Turismo, mas, após este ano, a instituição não ofereceu mais turmas para o curso. Parcerias já foram estabelecidas, relacionadas a projetos de extensão da Universidade com instituições como CTTI, IER e SEBRAE. Entretanto, alguns dos entrevistados em seus relatos apontaram que somente em casos isolados é que se desenvolvem açóes junto à universidade, não citando a existência de açóes com as demais instituiçóes. 
Existe a necessidade de desenvolver projetos de pesquisa e extensão relacionados à atividade turística na região. Além disso, demandas por capacitaçôes também poderiam ser atendidas pelas instituiçóes de ensino presentes na regiáo. Construir um planejamento de forma integrada e com instâncias de governança, poder público municipal e iniciativa privada, atendendo aos três pilares da educação: ensino, pesquisa e extensão; poderá gerar grandes benefícios para o setor de turismo e fortalecer a regionalidade.

Gerar conhecimento com estudos locais da realidade empresarial na cadeia do turismo, identificar necessidades e gargalos, verificar a eficácia de políticas públicas de turismo, disseminar informaçóes que geram o aprendizado coletivo, ainda não fazem parte das prioridades dos planos e projetos de turismo desenvolvidos. Tais valores podem ser construídos, a partir de parcerias e cooperaçóes institucionais, de forma a orientar a governança da atividade turística e também o desenvolvimento regional.

\section{Governança do desenvolvimento regional a partir do turismo}

Foi possível constatar, nesta pesquisa, existência de um nível relativamente avançado de governança no desenvolvimento da região, entretanto, foram identificadas discrepâncias entre os municípios analisados referentes à maior ou menor grau de elementos de governança que são atendidos no âmbito de cada cidade.

Com base nos relatos coletados, observa-se que em Tiradentes, em virtude do bom desempenho da atividade turística, existe uma consciência coletiva e alguns movimentos da sociedade local, orientados a encontrar saídas para problemas vivenciados pela população, que refletem e comprometem a atividade turística do município. Em contrapartida, existem problemas apontados como limitadores e restritivos ao turismo impactando diretamente a vida da população local e regional.

Apesar de a atividade turística, em muitos casos, ser considerada como degradadora do território e geradora de problemas sociais, caso não seja controlada e regulamentada, observa-se que, no caso em questão, existe uma série de benefícios como maior oferta de capacitação de pessoas, para atuar no setor; ampliação do mercado e toda a cadeia que envolve o turismo; captação de recursos e mais investimentos na manutenção e preservação do patrimônio público; geração de ocupação e renda para a populaçáo; oferta de mais atraçóes artísticas e culturais, envolvendo a população tanto no consumo destes serviços quanto na valorização da cultura local e artistas regionais; maior visibilidade e reconhecimento do município e região nível estadual e nacional.

Em São João Del Rei, apesar de ser uma cidade de porte maior que as demais e não possuir no turismo sua principal atividade econômica, pode-se observar como políticas públicas, projetos e açóes de turismo geram resultados para o desenvolvimento municipal, beneficiando sua população, seja no aspecto cultural e econômico, como na gestão pública municipal. Em razão de todo o conjunto arquitetônico tombado pelo IPHAN, a valorização do turista, quanto à cultura, tradiçóes e costumes locais, o turismo passou a ser um elemento influenciador na preservaçáo da riqueza material e imaterial. Em 2017, a cidade foi eleita a mais hospitaleira do Brasil, conforme o ranking produzido pela plataforma de hospedagem AirBnb. Investimentos na melhoria de infraestrutura de acesso, prioridade na realização e 
promoção de eventos culturais, que, inicialmente, teriam como foco atrair turistas para o município, gerou também benefícios à população, que passou a dispor de melhores serviços e bem-estar geral.

Prados, que até os anos de 1990 náo sinalizava pretensóes para o fortalecimento do turismo, viu seu distrito de Bichinho se destacando na atividade e, a partir dos anos 2000, passou a ampliar este caso bem-sucedido para todo o município. O poder público, desde 2007, vem buscando aproveitar o fluxo de turistas que frequenta Tiradentes e São Joáo Del Rei, para oferecer um roteiro integrado aos visitantes dos municípios, fortalecendo e desenvolvendo, principalmente, sua produção artesanal. O setor empresarial percebe o potencial de crescimento da atividade turística e busca estabelecer parcerias e se estruturar, em termos de comissões, para tomada de decisóes sobre turismo.

Foi possível constatar que, após a investigação das ações desenvolvidas pelos órgãos e instâncias de governança, para fortalecer o turismo na região, estruturas de decisôes como o comTur, instituiçóes de representação empresarial como Associaçóes Comerciais e Empresariais, comunidade local e entidades responsáveis pela promoção, articulaçáo e assessoramento de planos, programas e políticas são cruciais para o fortalecimento da atividade turística e o desenvolvimento regional.

Percebeu-se, também, que os resultados gerados pelas açóes de fortalecimento do turismo contribuíram para maior envolvimento da sociedade, integração de açôes, exercício da cultura da cooperação, valorização e preservação patrimonial, cultural, paisagístico e ambiental, qualificação profissional e, ainda, o sentimento de pertencimento àquela identidade regional.

Verificou-se que a articulação e governança das açốes desenvolvidas nos municípios se dão, a partir do CTTI, o qual possui relevante poder e influência sobre as açôes, projetos e programas realizados nos municípios e, ainda, é responsável por estabelecer um canal direto com o poder público na esfera estadual e federal em prol de necessidades da região. As açóes são planejadas, considerando os contextos regional e local, buscando integrar instituiçôes de apoio à atividade turística, fortalecendo e responsabilizando os Conselhos Municipais de Turismo na tomada de decisão e estabelecimento de diretrizes e prioridades na condução da atividade.

Foi constatado que os resultados gerados pelas açóes de fortalecimento do turismo para o Desenvolvimento Regional, a partir da Dimensão Organizacional proposta pelo modelo de Tomazzoni (2007), possibilitou maior entendimento dos municípios quanto à interdependência entre eles na consolidação da região como um destino turístico diversificado, com atrativos variados e complementariedades de produtos e serviços que agregam valor para as pessoas que desejam visitar a região e promove o desenvolvimento da comunidade.

Campo das Vertentes vem se destacando como um exemplo de governança para o desenvolvimento regional por meio do turismo, e os resultados vêm influenciando o modo como empresários, população e poder público planejam as atividades. Nesse sentido, о СтTі possui papel central na articulação, integração, estruturação e fortalecimento do turismo, fazendo da governança regional do turismo uma importante ferramenta de observação e prospecção do desenvolvimento regional. 


\section{Consideraçóes finais}

Os resultados gerados pelas açóes de fortalecimento do turismo para o Desenvolvimento Regional apontam, nos municípios analisados, transformações que necessitam ser melhor compreendidas, a fim de potencializar a atuação da regiáo como um consolidado destino turístico no cenário nacional.

Observou-se o relevante resultado referente ao marketing atrelado ao roteiro Estrada Real e a visibilidade conquistada pelos municípios a partir desse roteiro regional. Com esse forte apelo mercadológico, a região passou a ser divulgada nacional e internacionalmente, sendo fomentada por instituiçôes de apoio, políticas públicas direcionadas às necessidades regionais, profissionalização e estruturação de agentes e empresas do setor, ampliando assim os atrativos turísticos e gerando maior competitividade. Como consequência, o aumento de renda e ocupação consiste em um dos fatores mais visíveis apoiado no fortalecimento do turismo, tanto direta quanto indiretamente.

O artesanato, por exemplo, vem ganhando força na composição dos produtos turísticos, evidenciando a sua diversidade, valorizando e fomentando as tradiçôes regionais. Adicionalmente, foi possível observar o envolvimento da população, de forma mais intensa, no município de Tiradentes, nas decisóes e planejamento do turismo, sobretudo, pela representação e atuação do COMTUR. Entretanto, avalia-se a possibilidade de maior ação da comunidade cultural na governança do turismo na regiáo. Mesmo existindo a representatividade da comunidade no COMTUR, o município de São João Del Rei, ainda carece de maior atuação do Conselho nas decisôes relacionadas às atividades de turismo.

O Стті é a principal instância de governança do turismo na região, atuando como articulador e elo de ligação entre agentes municipais, como poder público e iniciativa privada e instâncias do poder público estadual e federal, juntamente com instituiçóes fomentadoras do turismo. Os resultados demonstram ainda que a governança regional existente atua de modo a sistematizar os interesses, estabelecendo prioridades, compreendendo as disparidades, mediando divergências políticas que estão enraizadas na região, aplicando, assim, mecanismos de forma a transacionar as ações realizadas na região, gerando reflexão entre os agentes acerca das necessidades regionais mais relevantes a serem superadas, a fim de construir públicas unificadas que fortaleçam o turismo regional e contribuam para desenvolvimento da sociedade.

Os resultados da pesquisa corroboram com os autores que deram sustentaçáo teórica para a pesquisa (стTı, 2010; Oliveira \& Fuchs, 2013; Oliveira \& Januário, 2007; Ramíres, Cortés, Osorio \& Nieto, 2017; setur, 2007; Tomazzoni, 2007).

O objetivo de analisar os resultados gerados pelas açóes de fortalecimento do turismo para o Desenvolvimento Regional, a partir da dimensão organizacional proposta pelo modelo de Tomazzoni (2007) foi plenamente atingido.

Os municípios de Prados, São João Del Rei e Tiradentes, localizados na região estudada por meio de pesquisa documental e entrevistas, analisados os dados coletados por meio de análise de conteúdo utilizando software Atlas ti, apresentam resultados que permitem afirmar que o protagonista principal é о СтTі, impulsionando o 
desenvolvimento da atividade turística na região, exercendo maior poder e influência que outros atores sociais. Pode-se registrar um desequilíbrio referente ao desenvolvimento das açóes de turismo em nível municipal, diretamente relacionado à organização do Conselho Municipal de Turismo de cada município. Outrossim, os resultados obtidos referem-se apenas à região Campo das Vertentes. Assim, sugerese para estudos futuros que se faça a mesma pesquisa em outras regióes brasileiras ou de outros países, permitindo comparaçôes.

\section{Referências bibliográficas}

Araujo, L. M. \& Dredge, D. (2012). Tourism development, policy and planning in Brazil. In G. Lohmann \& D. Dredge (eds.), Tourism in Brazil: Environment, Management and Segments (pp. 17-29). Nova York: Routledge.

Barbosa, L. G. M. (2008). Estudo de competitividade dos 65 Destinos indutores do desenvolvimento turístico regional. Relatório Brasil. Brasília: Ministério do Turismo.

Benko, G. \& Lipietz, A. (orgs.). (1994). As regiōes ganhadoras: distritos e redes, os novos paradigmas da geografia econômica (pp. 171-188). Oeiras, Portugal: Celta.

Boisier, S. (1998). Post-scriptum sobre desarrollo regional: modelos reales y modelos mentales. EURE (Santiago), 24(72), 53-69. http://dx.doi.org/10.4067/S025071611998007200003

Bramwell, B. \& Lane, B. (2011). Critical research on the governance of tourism and sustainability. Journal of Sustainable Tourism, 19(4-5), 411-421. https://doi.org/10.1 080/09669582.2011.580586

Brasil (2007). Ministério do Turismo. Plano Nacional de Turismo 2007-2010. Brasília, 2007a. Recuperado de: http://www.turismo.gov.br/turismo/o_ministerio/plano_nacional/ ebook/index.html

Circuito Turístico Trilha dos Inconfidentes (Стті) (2010). O que é um circuito? Recuperado de: http://www.trilhadosinconfidentes.tur.br/institucional.php

Cirino, J. F. \& Lima, J. E. D. (2008). Valoração contingente da Área de Proteção Ambiental (APA) São José-MG: um estudo de caso. Revista de Economia e Sociologia Rural, 46(3), 647-672. http://dx.doi.org/10.1590/S0103-20032008000300004

Dallabrida, V. R. (2011). Governança territorial e desenvolvimento: as experiências de descentralização político-administrativa no Brasil como exemplos de institucionalização de novas escalas territoriais de governança. Instituto de Pesquisas Econômicas Apicadas (IPEA). Code. Recuperado de: https://www.unc.br/mestrado/textos/artigo-ipeagovernanca-territorial-e-desenvolvimento-valdir.pdf.

Dallabrida, V. R., Siedenberg, D. R. \& Fernández, V. R. (2004). Desenvolvimento a partir da perspectiva territorial. Desenvolvimento em questão, Ijuí, 04(1), 33-62. https://doi. org/10.21527/2237-6453.2004.4.33-62

Dreher, M. T. \& Salini, T. S. (2010). Governança e Políticas Públicas de Turismo em Gaspar, Santa Catarina. Anais de Seminário de Pesquisa em Turismo do MERCOSUL SeminTUR. 6. Caxias do Sul, Rs, Brasil. 
Gil, A. C., Oliva, E. C. \& Silva, E. C. (2009). Turismo e regionalidade. Turismo-Visão e Ação, 11(1), 92-111. http://dx.doi.org/10.14210/rtva.v11n1.p92\%20-\%20111

Guia Quatro Rodas (2012). A gente vai antes para você ir melhor. São Paulo: Editora Abril. Recuperado de: https://viagemeturismo.abril.com.br/

Jamal, T. \& Getz, D. (1999). Community roundtables for tourism-related conflicts: The dialectics of consensus and process structures. Journal of Sustainable Tourism, 7(3-4), 290-313. https://doi.org/10.1080/09669589908667341

Lohmann, G. \& Dredge, D. (Eds.). (2012). Tourism in Brazil: Environment, management and segments. Nova York: Routledge.

Klink, J. J. (2001). A cidade-regiāo: regionalismo e reestruturação no grande ABC paulista. Rio de Janeiro: DP\&A Editora.

Mattar, F. N. (1996). Pesquisa de Marketing. Edição Compacta. São Paulo: Atlas.

Medina, V. (2017). Las movilidades poblacionales y su impacto territorial en la estructura espacial de las ciudades turísticas: El caso de San Carlos de Bariloche. EURE (Santiago), 43(129), 71-92. http://dx.doi.org/10.4067/S0250-71612017000200004

Mello, R. B. (2006). Softwares em pesquisa qualitativa. Pesquisa qualitativa em estudos organizacionais: paradigmas, estratégias e métodos. São Paulo, sP: Saraiva.

Neves, R. \& Carneiro, E. J. (2014). Empreendedorismo e marketing urbano: a mercadorização do centro "histórico" de Tiradentes, Minas Gerais, na ótica do turismo. Revista Cenário, 2(2), 65-81. Recuperado de: http://periodicos.unb.br/index.php/revistacenario/ article/view/10898/8292

Neves, R. \& Carneiro, E. J. (2012). Imagens do Patrimônio e Turismo: Metamorfoses e "Mercadorização" do Território Central de Tiradentes, Minas Gerais. Revista Espaço e Geografia, 15(2), 407-441. Recuperado de: http://www.lsie.unb.br/espacoegeografia/ index.php/espacoegeografia/article/view/174/164

Oliveira, F. F. D. \& Fuchs, A. M. S. L. (2013). O planejamento turístico participativo na gestão do Circuito Turístico Trilha dos Inconfidentes/Mg. NAU Social, 4(6), 100-119. Recuperado de: http://www.periodicos.adm.ufba.br/index.php/rs/article/viewArticle/241

Oliveira, S. T. \& Januário, M. V. C. (2007). O Turismo em São João Del Rei Minas Gerais: Uma Análise Preliminar. CULTUR: Revista de Cultura e Turismo, 1(1), 1-10. Recuperado de: http://periodicos.uesc.br/index.php/cultur/article/view/219

Paixão, L. M. (2013). Arranjos produtivos locais, governança territorial e desenvolvimento turístico no meio rural: o caso das regiōes turísticas da Serra Gaúcha, Bonito e Treze Tílias. (Dissertação de mestrado) Programa de Pós-Graduação em Desenvolvimento Regional e Urbano), Universidade de Salvador. Salvador, BA, Brasil.

Prefeitura do Município de São João Del Rei (2017). Cultura e Turismo. Eventos Culturais. Recuperado de: http://saojoaodelrei.mg.gov.br/pagina/7208/Eventos\%20Culturais

Prefeitura do Município de Prados (2017). Cultura. Eventos anuais. Recuperado de: http:// prados.mg.gov.br/pagina/1756/Eventos

Prefeitura do Município de Tiradentes (2017). Calendário de eventos. Recuperado de: http:// www.tiradentes.mg.gov.br/pagina/6451/Calend\%C3\%A1 rio\%20de\%20Eventos

Ramírez, I., Cortés, I., Osorio, M. \& Nieto, R. (2017). ¿Así son, así se imaginan ellos, o así los imaginamos?: Reflexiones sobre las transformaciones socioterritoriales del turismo residencial en Malinalco, México. EURE (Santiago), 43(129), 143-164. http://dx.doi. org/10.4067/S0250-71612017000200007 
Ramos, B. A. (2007). A formaçāo de Circuitos turísticos como forma de atração e permanência de visitantes: uma avaliação dos gestores sobre os fatores de atratividade dos circuitos turísticos de Minas Gerais. (Dissertação de Mestrado) Programa de Pós-Graduação em Turismo e Meio Ambiente. Centro Universitário UnA, Belo Horizonte, MG, Brasil.

Reich, B. H. \& Benbasat, I. (1996). Measuring the linkage between business and information technology objectives. MIS Quarterly, 20(1), 55-81. http://dx.doi.org/10.2307/249542

Rodrigues, L. M., Silva, M. N. S. \& Diniz, R. F. (2012). Artesanato mineiro: limites e possibilidades da atividade artesã no município histórico de Prados/Mg. Revista Eletrônica de Geografia, 4(11), 62-85. Recuperado de: http://www.observatorium. ig.ufu.br/outubro2012.htm

Rotta, E., Fraga, C. K., Preuss, L. T. \& Ames, M. A. C. (2006). As políticas sociais como potencializadoras do desenvolvimento local-regional. Textos \& Contextos. Porto Alegre, 5(1), 1-21. http://dx.doi.org/10.15448/1677-9509

Rotta, E. (2007). Desenvolvimento Regional e politicas sociais no noroeste do estado do Rio Grande Do Sul. 2007. (Tese de Doutorado) Programa de Pós-Graduação em Serviço Social, Pontifícia Universidade Católica do Rio Grande do Sul. Porto Alegre, Rs, Brasil.

Santos, S. R. \& Gomes, C. M. (2007). Políticas públicas de turismo: a importância para o desenvolvimento do Maranhão. Anais da Jornada Internacional de Politicas Públicas. 3. São Luiz, MA, Brasil.

Santos, T. S. (2011). Desenvolvimento local e artesanato: uma análise de dois municípios de Minas Gerais. (Dissertação de mestrado) Departamento de Administraçáo e Economia. Universidade Federal de Lavras. Lavras, MG, Brasil.

Secretaria de Estado do Turismo de Minas Gerais (setur). (2007) Circuitos turísticos. Recuperado de: http://www.turismo.mg.gov.br/circuitos_turisticos.php.

Silveira, G. T. (2008). Turismo, emprego e renda: o caso da cidade histórica de Tiradentes - mg. (Dissertação de mestrado) Programa de Pós-Graduação em Turismo) - Universidade de Caxias do Sul. Caxias do Sul, Rs, Brasil.

Souza, M., Warley, J., Shiki, F. N. S. \& Pereira, P. A. R. (2015). Desarrollo Sustentable: Un índice para el Circuito Turístico Trilha dos Inconfidentes-Minas Gerais, Brasil. Estudios y perspectivas en turismo, 24(3), 547-569. Recuperado de: http://www.scielo.org.ar/ scielo.php?script=sci_arttext\&pid=S1851-17322015000300006

Stoffelen, A. \& Vanneste, D. (2016). Institutional (dis) integration and regional development implications of whisky tourism in Speyside, Scotland. Scandinavian Journal of Hospitality and Tourism, 16(1), 42-60. https://doi.org/10.1080/15022250.2015.1062416

Storper, M. \& Harrison, B. (1994). Em G. Benko \& A. Lipietz (orgs.), As regiöes ganhadoras: distritos e redes, os novos paradigmas da geografia econômica (pp. 171-188). Oeiras, Portugal: Celta

Tomazzoni, E. L. (2007). Turismo e desenvolvimento regional: modelo apl tur aplicado à regiáo das Hortênsias (Rio Grande do Sul-Brasil). (Tese de doutorado) Escola de Comunicaçóes e Artes, Universidade de São Paulo. São Paulo, sp, Brasil.

Yin, R. K. (2015). Estudo de Caso: Planejamento e Métodos. Porto Alegre: Bookman editora. 
